\title{
Estimating population size, structure, and residency time for whale sharks Rhincodon typus through collaborative photo-identification
}

\author{
Jason Holmberg $^{1,2, *}$, Bradley Norman ${ }^{3}$, Zaven Arzoumanian ${ }^{2,4}$ \\ ${ }^{1}$ ECOCEAN USA, 4836 NE 31st Avenue, Portland, Oregon 92711, USA \\ ${ }^{2}$ Centre for Fish and Fisheries Research, Murdoch University, South Street, Murdoch, Western Australia 6150, Australia \\ ${ }^{3}$ ECOCEAN, c/o Centre for Fish and Fisheries Research, Murdoch University, South Street, Murdoch, \\ Western Australia 6150, Australia \\ ${ }^{4}$ Present address: Universities Space Research Association, 10211 Wincopin Circle, Columbia, Maryland 21044, USA
}

\begin{abstract}
Capture-mark-recapture (CMR) data from Ningaloo Marine Park (NMP) in Western Australia have recently been used to study the population dynamics of the local whale shark aggregation. Because nascent research efforts at other aggregation points look to NMP as a model, further analysis of existing modeling approaches is important. We have expanded upon previous studies of NMP whale sharks by estimating CMR survival and recruitment rates as functions of average total length (TL). Our analysis suggests a decline in reported values of TL coincident with marginally increasing abundance among sharks sighted in more than one year ('returning') from 1995 to 2008. We found a positive, average returning recruitment rate $(\lambda)$ of $1.07 \mathrm{yr}^{-1}(0.99$ to $1.15,95 \% \mathrm{CI})$; smaller individuals contributed in larger numbers to recruitment, allowing for population growth accompanied by a decline in median size. We subsequently explored intraseasonal population dynamics with the Open Robust Design (ORD) model structure. Our best-fit model estimated modestly increasing annual abundances between 107 (95\% CI = 90 to 124) and 159 (95\% CI = 127 to 190) for 2004 to 2007 , suggesting a short-term increase in total annual abundance. The ORD also estimated an average residency time of $33 \mathrm{~d}(95 \% \mathrm{CI}=31$ to 39$)$ and biweekly entry profiles into the study area. Overall, our techniques demonstrate how large aggregations of the species can be modeled to better understand short- and long-term population trends. These results also show the direct scientific benefit from the development of an online, collaborative data management system to increase collection of sighting data for a rare species in conjunction with ecotourism activity.
\end{abstract}

KEY WORDS: Mark-recapture - Open Robust Design - Population biology - Rhincodon typus · Survivorship · Transience $\cdot$ Whale shark

Resale or republication not permitted without written consent of the publisher

\section{INTRODUCTION}

Whale sharks Rhincodon typus are the world's largest living fish and have a broad distribution in tropical waters. Despite growing numbers of encounters with the species through ecotourism, little or no information is available on key aspects of whale shark biology, such as age-specific growth rates, reproductive rates, pup survival rates, and breeding habitats. The whale shark is assessed as Vulnerable in the IUCN Red List of Threatened Animals (IUCN 2008), but available reports of local population trajectories (CITES 2002, Theberge \& Dearden 2006, Bradshaw et al. 2007, Holmberg et al. 2008) are not set within a well-understood life history framework. Broader interpretation of the status of the species, especially in the Indian Ocean, is confounded by minimal knowledge of the role that many unlinked sighting locations play along poorly understood migration routes.

Whale sharks are an ideal species for new, computer-assisted mark-recapture efforts supported by pattern recognition software. The distinctive patterns 
of lines and spots on their flanks provide individualized markers that can be distinguished by eye or using available computer algorithms (Arzoumanian et al. 2005, Van Tienhoven et al. 2007). Whale shark ecotourism industries have been established at several aggregation points, such as Ningaloo Marine Park (NMP) in Western Australia, Mozambique, the Galapagos Islands, the Philippines, the Maldives, the Seychelles, Honduras, Belize, and Mexico. The integration of large scale photo-identification with ecotourism has resulted in increased data collection (Holmberg et al. 2008). However, modern mark-recapture efforts have only begun to estimate localized population trends for whale sharks in the past several years, and resulting population trajectory estimates are only available for a single study site: NMP.

Two publications (Bradshaw et al. 2007, Holmberg et al. 2008) have produced population trajectory estimates for whale sharks at NMP using different modeling approaches. In a mark-recapture study of 111 ind. over the years 1992 to 2004, Bradshaw et al. (2007) presented several modeling outcomes based on a Leslie Matrix model. Population growth rate $(\lambda)$ estimates varied from 0.87 to $1.26 \mathrm{yr}^{-1}$, depending on the biological assumptions used in the model structure. Ten of 16 models reported a decline in $\lambda$ for all sharks visiting NMP, with values ranging from 0.85 to 0.97 . In contrast, Holmberg et al. (2008) estimated $\lambda$ at $1.12 \mathrm{yr}^{-1}(\mathrm{SE}=0.06)$ in a capturemark-recapture (CMR) analysis using the CormackJolly-Seber (CJS) (Lebreton et al. 1992) and Link-Barker Jolly-Seber (LBJS) (Link \& Barker 2005) models for the subset of sharks returning to the reef in more than one year of the study. While not immediately contradictory, the contrasting broader implications of the population decline vs. population growth conclusions drawn by these studies - which inform management practices at NMP and potentially elsewhere - suggest the need for more detailed analysis.

The determination of age and growth rates is important to the study of population dynamics in elasmobranchs (Cailliet et al. 2006), with survival probability likely to increase as individuals grow and predation risk decreases. Therefore, improved population models for whale sharks might be generated by incorporating total length (TL) as a covariate (Bradshaw et al. 2007). Herein, we explore average TL as a refining covariate to our previous study (Holmberg et al. 2008). Analyzing CMR survival and recruitment as a function of TL can provide insight into the size categories of sharks contributing to population trends, ensuring that averaged estimates are not masking underlying trends in the dataset. The present study also examines the applicability of the Open Robust Design (ORD) model structure (Schwarz \& Stobo 1997, Kendall \& Bjorkland 2001) to whale shark population dynamics on a finer time scale. Specifically, the ORD allows for the analysis of intraseasonal behavior, such as residency time and probabilities of entering and leaving the study area within a season. The ORD can also generate annual estimates of total abundance, providing a new look at population size in the presence of transience.

Although whale sharks are a migratory species, localized mark-recapture and modeling efforts continue to be a necessity. Of 1275 whale sharks collaboratively tagged off Australia, Christmas Island, the Maldives, Mozambique, the Philippines, the Seychelles, Thailand, and elsewhere within the region, only 3 have been sighted at more than one of these study locations (ECOCEAN Whale Shark Photo-identification Library, www.whaleshark.org). None of 491 whale sharks tagged from NMP have been recorded elsewhere, and available satellite tracks (CSIRO Marine and Atmospheric Research, www.cmar.csiro. au/tagging/whale/ningaloo.html) show the potential for multiple migration routes away from the park. Until potential relationships between aggregation points can be established, localized population trajectories must continue to serve as a guide to the pressures on the species. Our new analyses provide deeper insight into the local whale shark population trajectory at NMP and suggest replicable model starting points for the examination of other aggregations of the species. In a broader context, our approach to collaborative data collection and management for a rare marine species using ecotourism as a means to increase available CMR data, as well as the resulting models, may provide a template for research into other threatened species with similar occurrence patterns.

\section{MATERIALS AND METHODS}

Study area. Our research was conducted at NMP in Western Australia (Fig. 1). The boats and spotter planes used daily during the annual whale shark aggregation (March to July) at NMP provide direct access for monitoring the study population. We limited our study area to the northern ecotourism zone (North Ningaloo) based out of Exmouth, after our previous study (Holmberg et al. 2008) demonstrated that modeled capture probability estimates may be confounded when occurrence data from the northern and southern (Coral Bay) areas are combined. This may suggest some site-specific behavior within NMP, or it may be an artifact of the dataset that will be resolved with subsequent years of collection.

We note that the observed whale shark population consists predominately of immature males (Meekan et al. 2006, Holmberg et al. 2008), and throughout the present study there was no evidence of mating activity, 


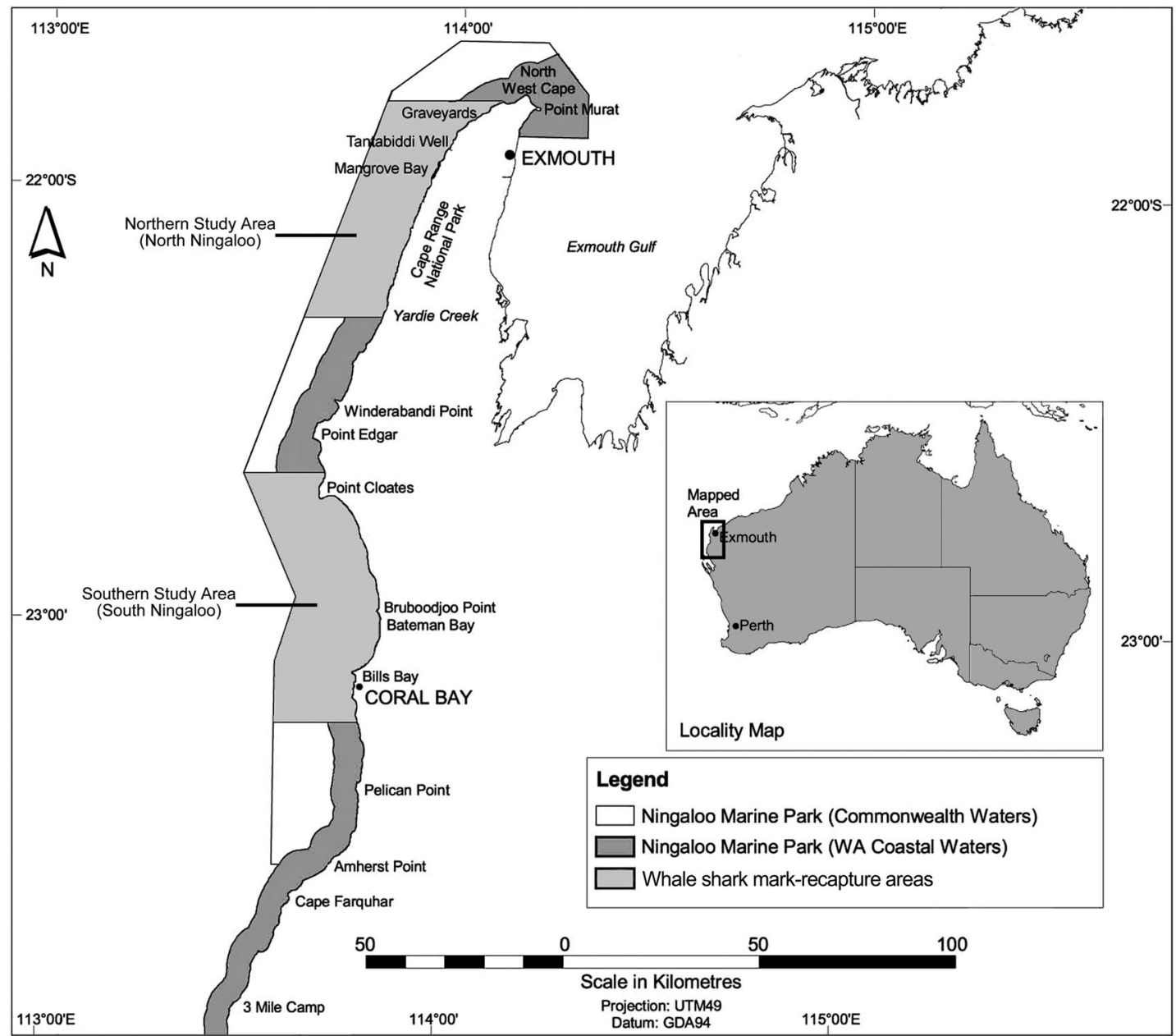

Fig. 1. Ningaloo Marine Park, Western Australia. Whale shark mark-recapture data in the present study were collected solely out of the northern study area, North Ningaloo. Map supplied courtesy of the Western Australian Department of Environment and Conservation

births, or deaths. Observed behavior suggests that NMP serves primarily as a feeding station (Taylor 1996) on one or more migration routes. However, while evidence exists for genetic linkage between populations (Castro et al. 2007), whale sharks from NMP have not been identified at any other known aggregation point in the Indian Ocean.

Data collection. We collected photographs and occurrence data from over 450 individual contributors, including the authors, the tourism community, and local resource managers. Occurrence data included encounter dates, estimates of total length, photographs of relevant spot patterning and scarring, and sex. Photographs and videos used for identification of individuals for mark-recapture were taken in the water. The spots along the flanks of whale sharks do not change significantly over time for the size range of whale sharks found at NMP (Arzoumanian et al. 2005) and have been used to distinguish individuals in a number of studies (Taylor 1994, Norman 1999, Arzoumanian et al. 2005, Meekan et al. 2006, Bradshaw et al. 2007, Holmberg et al. 2008). Two algorithms were employed for computer-assisted photo-identification based on spot patterning (Arzoumanian et al. 2005, Van Tienhoven et al. 2007), permitting rapid identification for mark-recapture analysis.

All collected data were entered by contributors into the online, public interface of the ECOCEAN Whale Shark Photo-identification Library (www.whaleshark. org). The ECOCEAN Library shares whale shark research data and a standardized software tool suite among participating individuals from the academic and conservation communities. The ECOCEAN Library also centrally houses the pattern matching algorithms used for computer-assisted identification and exports capture history files for the statistical models and modeling software used in the present study (see 'Modeling'). 
Pattern recognition algorithms. The 2 spot pattern recognition algorithms used in the present study (Arzoumanian et al. 2005, Van Tienhoven et al. 2007) to identify captured individuals were independently developed and take different approaches to pattern comparison. The $\mathrm{I}^{3} \mathrm{~S}$ algorithm presented by Van Tienhoven et al. (2007) measures distances between potential point matches mapped into a common space, ranking matches according to a distance metric. The smaller the metric is, the more likely that the potentially matched spots correspond between images and the greater the probability of the match. Arzoumanian et al. (2005) present a separate methodology based on the creation and comparison of triangles of spots to measure the relationships between groups of potentially matched spots. The comparison metric generated increases in value as the number of triangles shared between 2 images increases. Both algorithms were employed for initial identifications and, following the methodology of Arzoumanian et al. (2005), we extracted at least one properly oriented, left-side pattern of spots, represented as $x, y$ coordinates within the image, for entry of a shark into the monitored population of the present study. Recaptures were made with the assistance of both algorithms or by visual comparison where improper orientation of the photographer to the shark prevented accurate automated pattern analysis. The simultaneous use of the algorithms minimized the likelihood of misidentification by providing 2 independent reports of potential matches. Additionally, a software-based photo keyword system allowed for rapid review of collected photographs for secondary identification characteristics, such as scarring, unusual patterning characteristics, or gill damage (www.whaleshark.org/wiki/doku.php?id=photo_ keywords). All identifications were reviewed and approved by 2 or more of the authors.

Our dataset may include multiple spot patterns for individuals sighted more than once. These multiple patterns, extracted from images taken hours or years apart, are obtained under real-world conditions where the degree of skew affecting the relationships between spots in a 2-dimensional photo varies from image to image and affects the algorithms' potential to find matches. A shark sighted more frequently is therefore more likely to be accurately identified by a new scan across the database than a shark sighted only once before, a caveat noted by the developers of both algorithms (Arzoumanian et al. 2005, Van Tienhoven et al. 2007). We therefore note the importance of statistical tests for heterogeneity in capture probability (see 'Modeling') to ensure that the algorithms do not introduce bias into collected data.

Given no evident systematic overlap between the approaches of the algorithms, we can multiply the average misidentification probability reported by
Arzoumanian et al. (2005) of 0.14 and the average for the 'Exhaustive Search' categories presented by Van Tienhoven et al. (2007) of 0.13 to generate a misidentification probability of 0.02 in our dual implementation. This value fits anecdotally with our experience correcting allocations when subsequent identifications clarify a match. We note that these previously published misidentification estimates for our implemented algorithms are based on real-world data. However, to further reduce misidentification, we also implemented peer review of all identifications, using 2 reviewers (J. H. and B. N.) with 6 and 14 yr of whale shark markrecapture experience, respectively.

Modeling. In the present study, we expanded upon our previous modeling approach (Holmberg et al. 2008), which estimated an average annual NMP population trajectory for sharks sighted in more than one year using the CJS (Lebreton et al. 1992) and LBJS (Link \& Barker 2005) models (Fig. 2). In our models' notation here, we label the whale sharks sighted in multiple years as 'returning'; we refer to the large number of sharks sighted in only one year in our study area as 'transient'; and we refer to sharks at first capture as 'new'. Given 2 additional years of data, we analyzed the impact of average TL on estimated apparent survival, recruitment, and capture probabilities when included as a covariate in our tested model structures.

We note an important limitation in the use of TL for whale sharks. Its incorporation in a multi-year study requires either accurate measurements for each marked animal for each capture period or mathematical expressions based on empirical, representative data to estimate growth for years in which no data is available. Alternatively, missing length values can be imputed from those available via the continuous covariate analysis of Bonner \& Schwarz (2006). Unfortunately, length estimates for whale sharks when collected from mixed contributors are prone to error. Graham \& Roberts (2007) and Norman \& Stevens (2007) listed standard errors (SEs) of $50 \mathrm{~cm}$ using trained research divers to estimate length. Growth rates between 3 and $70 \mathrm{~cm} \mathrm{yr}^{-1}$ were derived from these estimates for 3 male whale sharks observed at Gladden Spit, Belize, ranging in size from 4.5 to $8.5 \mathrm{~m}$ at first capture (Graham \& Roberts 2007). Uchida et al. (2000) reported mean growth rates of 21.6 to $29.5 \mathrm{~cm} \mathrm{yr}^{-1}$ for 3 whale sharks in an aquarium for periods ranging from 458 to $2056 \mathrm{~d}$. These annual growth estimates are within the SE for estimates made visually by observers, confounding attempts to generate accurate annual growth estimates.

In the absence of a system of comprehensive annual measurements, we assumed the average of all reported lengths for an individual to be a representative average TL over the course of the present study. Given the slow projected growth rate of whale sharks 
(a) A-001: Basic Cormack-Jolly-Seber $\Phi\left(t_{1}\right) p\left(t_{1}\right)$

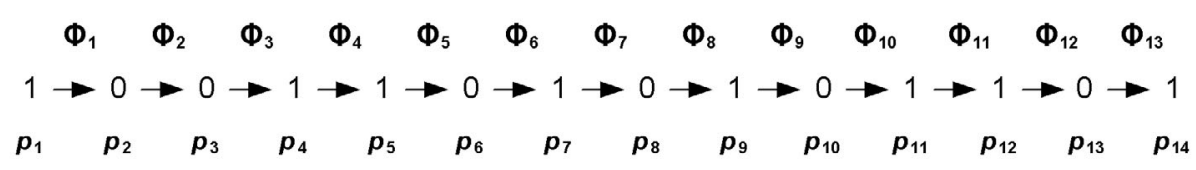

(b) A-001: Basic Link-Barker Jolly-Seber $\Phi\left(t_{1}\right) p\left(t_{1}\right) f\left(t_{1}\right)$

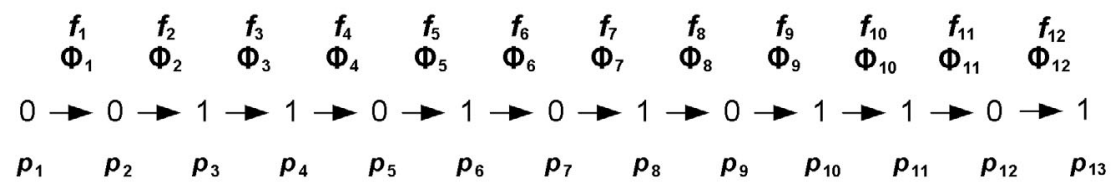

(c) A-001: Basic Open Robust Design $S\left(t_{1}\right)$ pent $\left(t_{2}\right) P h i\left(t_{2}\right) p\left(t_{2}\right)$

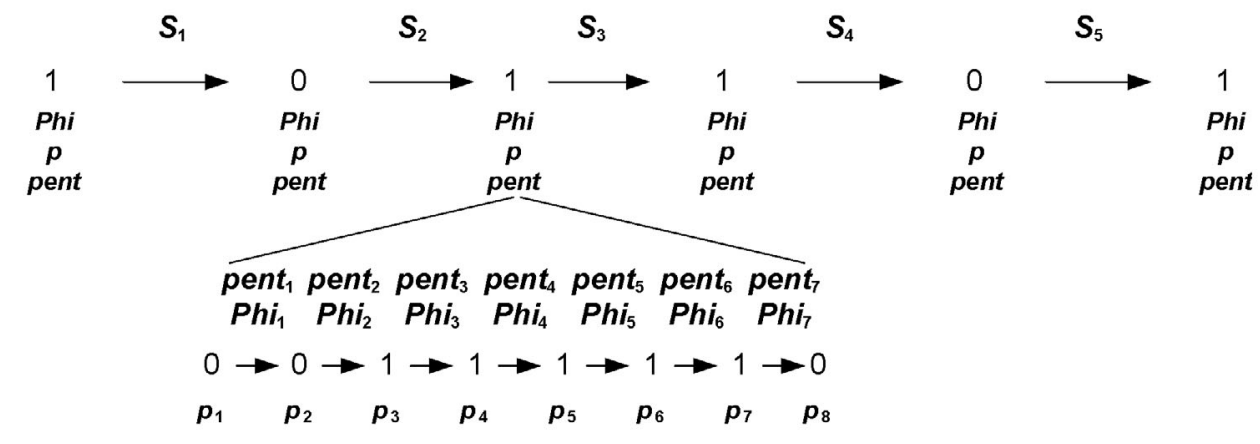

\begin{tabular}{l}
\hline Legend \\
$\Phi$ and $S-$ Annual apparent survival rate \\
$\boldsymbol{p}-$ Capture probability \\
$\boldsymbol{f}$ - Recruitment rate \\
pent - Probability of entry into the study area \\
$P \boldsymbol{h i}$ - Probability of remaining in the study area \\
$\boldsymbol{t}_{1}-$ Primary (annual) time interval \\
$\boldsymbol{t}_{2}-$ Secondary (intra-seasonal) time interval
\end{tabular}

Fig. 2. Rhincodon typus. Example capture history for a marked whale shark (A-001) and the parameters estimated under the fully parameterized versions of 3 model structures used in the present study

(Colman 1997) and the low numbers of individuals identified in multiple seasons (Meekan et al. 2006, Holmberg et al. 2008), this assumption may have good statistical validity, though it does not account for the biological reality of growth of immature individuals over time. Unfortunately, data were too sparse to implement the continuous covariate analysis of Bonner \& Schwarz (2006).

Modeling intraseasonal population dynamics can provide deeper insight into the behavior of a study group (Crosbie \& Manly 1985). We therefore examined the ORD (Schwarz \& Stobo 1997, Kendall \& Bjorkland 2001) model structure for application to whale sharks, the first such attempt. The ORD models the apparent survival probability $(S)$ between annual primary periods $\left(t_{1}\right)$, as well as intraseasonal statistics of capture probability $(p)$, probability of entry (pent), and probability of remaining in the study area $(P h i)$ for eight 2 wk secondary sampling periods $\left(t_{2}\right)$ (Fig. 2). The ORD can also be used in a multistate context, providing probability estimates for the shift of individuals between states $(\Psi)$, such as locations or behavioral characteristics, and allowing model variables to be estimated independently for each stratum (Nichols \& Kendall 1995, Kendall \& Bjorkland 2001).

Under the ORD, the study population is open to gains and losses between primary periods. For secondary periods, the population is also open, but gains and losses are assumed to be the result of staggered 
entries and exits rather than mortality or permanent emigration. We defined 8 secondary periods representing $15 \mathrm{~d}$ sampling sessions from 1 April to 31 July for the years 2003 to 2008 to achieve a good balance between occurrence data and the number of terms estimated in the model structure. This range spans all but the earliest arrivals on the reef in late March for which few data were available.

As an additional output, the ORD model generates estimates for intraseasonal residency time, providing a measure of the average amount of time that individual whale sharks spend at North Ningaloo each season. The ORD can also provide a measure of aggregate abundance $(\mathrm{N})$ for each primary period through its underlying use of the Jolly-Seber model (Jolly 1965, Seber 1965). Annual estimates of abundance from our use of the ORD represent the total number of animals that visited the reef during the season from April to July. Previous estimates have placed the number of whale sharks annually visiting NMP from a maximum of 1300 (CSIRO media release, www3. aims.gov.au/news/pages/media-release-20050308.html) to between 319 and 436 (Meekan et al. 2006) using the Jolly-Seber model to a minimum estimate by Taylor (1994) of 200 ind. Annual estimates of abundance produced via the ORD may refine this range.

Use of the Jolly-Seber modeling structure within the ORD requires the following assumptions:

- Homogeneity in capture probability among marked individuals. Our previous study (Holmberg et al. 2008) demonstrated the validity of this assumption. For thoroughness, we retest this assumption in the present study by implementing Test 2 (Burnham et al. 1987), which checks for significant heterogeneity in capture probability among marked individuals by analyzing whether a shark's capture probability is dependent upon when it was initially captured.

- Homogeneity in apparent survival (including death and permanent emigration) among marked individuals. Using Test 3 (Burnham et al. 1987), our previous study demonstrated a violation of this assumption due to the large number of whale sharks appearing in only one season at Ningaloo. To compensate, we presented a modeling alternative that used a survival dichotomy to account for this violation, estimating survival after the first sighting year $\left(\phi_{\text {new }}\right)$ separately from survival between subsequent resighting years $\left(\phi_{\text {return }}\right) . \phi_{\text {new }}$ effectively separates out the effect of transience (sharks sighted in only one year) from the apparent $\phi_{\text {return. }}$. Here, we test this modeling alternative in the context of the ORD.

- No tag loss or misidentification (sampling errors). Our use of the whale shark's natural spot patterning, which does not change significantly over time for the size range of whale sharks found at NMP (Arzouman- ian et al. 2005), ensures that tag loss is not a factor. We contend that misidentification, as previously discussed, is minimal in the context of the present study.

- Instantaneous sampling time relative to the time between samples, ensuring that birth, death, immigration, and emigration do not occur during the sampling process. In the context of secondary (intraseasonal) time periods under the ORD in the present study, the assumption of instantaneous sampling must be carefully examined given the 8 adjoined 2 -wk secondary sampling periods used for each annual season. While we note that whale shark births and deaths are not observed at NMP, the emigration of sharks from the study area within secondary sampling periods, if indicative of non-random behavior among marked individuals, can create a bias in estimates of Phi (Smith \& Anderson 1987, Williams et al. 2002) and demonstrate a violation of this assumption. We therefore checked for a systematic effect due to time since marking (TSM) in a shark's probability of remaining in the study area.

- Unmarked animals within the study population have the same probability of capture as marked individuals. This assumption is supported by the lack of trap response evident in whale sharks visiting North Ningaloo (Holmberg et al. 2008).

We used the software package CloseTest (version 3, Stanley \& Burnham 1999) to implement the closure tests of Otis et al. (1978) and Stanley \& Burnham (1999), checking our assumption of an open population. We used Program RELEASE GOF as implemented in MARK 5.1 (White \& Burnham 1999) to test for violations of model assumptions due to heterogeneity in capture probability (Test 2) and survival (Test 3).

For CJS, LBJS, and ORD model construction, we used MARK 5.1 to evaluate candidate models. All capture history files used for modeling were exported directly from the ECOCEAN Library. Best-fit model determination in MARK followed the normalized weights of the corrected Akaike's Information Criterion $\left(\mathrm{AIC}_{\mathrm{c}}\right.$ ) (Akaike 1973, Burnham \& Anderson 1992, Burnham \& Anderson 1998). CJS model rankings were adjusted using the median variance inflation factor ( $\hat{c})$ calculated through MARK (Lebreton et al. 1992). Median $\hat{c}$ values closer to unity indicate minimal overdispersion relative to the underlying multinomial models and provide evidence of an overall goodness of fit.

\section{RESULTS}

\section{Data collection}

As part of the present study, 6064 digital images of whale sharks at NMP were collected, representing a 
total of 2063 live captures recorded in the North Ningaloo study area from March to July 1995-2008. A total of 1668 captures (81\%) contained sufficient data for the identification of 386 sharks. Of these sharks, 219 (57\%) were males, 46 (12\%) were females, and $121(31 \%)$ were of indeterminate sex. Of the 1668 usable reports, 386 represented unmatched, first encounters of an individual, 985 were repeat identifications of previously identified individuals matched via pattern recognition software, and 277 represented previously identified individuals matched visually. In the present study, 250 of the sharks were captured in only one year, while 136 were sighted in at least $2 \mathrm{yr}$. It is important to note that this dataset represents both a 2 yr extension of the one used in our previous study (Holmberg et al. 2008) as well as a $41 \%$ increase in the number of identified sharks at North Ningaloo through identifications made by data-mining previously unincorporated video catalogs from past years.

Of all identified individuals, 287 (74\%) had at least one reported TL. The true SE for data from our mixture of experienced and inexperienced contributors is unknown. We assume an average SE of $1 \mathrm{~m}$, which is double the reported value for a trained researcher (Graham \& Roberts 2007, Norman \& Stevens 2007).

\section{Testing open population model assumptions}

We started our analysis by checking our open population model assumptions, using statistical tests for closure for primary (annual) periods. These tests produced low $p$-values $(\cong 0)$, indicating violation of the assumptions of closure. Taking an open population approach, we ran tests for homogeneity of capture and survival probabilities (Test 2 and Test 3) among individuals for primary periods. Our dataset did not fail these tests, yielding $p$-values $>0.19$. These results support the underlying assumptions of the CJS and ORD models in the context of the whale shark aggregation at North Ningaloo. They also provide verification that our use of available pattern recognition algorithms (Van Tienhoven et al. 2007, Holmberg et al. 2008) does not introduce resighting bias into model results. Intraseasonal data were insufficient to test assumptions of homogeneity in capture probability among marked individuals within the secondary periods of 2003 to 2008. However, we know of no systematic behavior, such as significantly different residency times among marked individuals, that would cause intraseasonal heterogeneity in capture probability while allowing capture probability for primary periods to remain homogeneous under the available tests.

\section{Evaluating the potential impact of total length as a model covariate}

To determine the potential impact of TL on the modeled results of our previous study (Holmberg et al. 2008) with our expanded dataset, we first constructed a set of CJS-based models for the primary periods of 1995 to 2008 in MARK without TL as a covariate. The best-fit model $\phi_{\text {new }}(.) \phi_{\text {return }}() p.(t)$, where (.) indicates a constant value and $t$ is the time interval, was identical to that derived previously and exhibited minimal overdispersion and an excellent fit to the dataset overall (median $\hat{\mathrm{c}}=1.13 \pm 0.01 \mathrm{SE}$ ). The average apparent survival probability for new sharks was estimated at $0.52 \mathrm{yr}^{-1}(95 \% \mathrm{CI}=0.45$ to 0.60$)$ and $0.87 \mathrm{yr}^{-1}(95 \% \mathrm{CI}$ $=0.83$ to 0.90 ) for sharks returning to North Ningaloo in more than one season.

Following our previous methodology (Holmberg et al. 2008), we then applied a reduction to the dataset (Pradel et al. 1997), removing the first capture occasion for all sharks, to model only the dynamics of the returning subset of 136 sharks using the LBJS model (Link \& Barker 2005), which models apparent recruitment per existing member of the population $(f)$ in addition to apparent survival probability $(\phi)$ and capture probability $(p)$. The resulting best-fit model $\left(\mathrm{AIC}_{\mathrm{c}}\right.$ weight $=$ $0.85)$ of $\phi_{\text {return }}(.) p_{\text {return }}(t) f_{\text {return }}($.$) estimated an average$ annual $\phi$ of $0.82 \mathrm{yr}^{-1}(95 \% \mathrm{CI}=0.77$ to 0.87$)$ and an average annual recruitment rate of $0.25 \mathrm{yr}^{-1}(95 \% \mathrm{CI}=$ 0.19 to 0.32 ), whose sum yields an average estimated $\lambda$ for the returning population of $1.07 \mathrm{yr}^{-1}(95 \% \mathrm{CI}=0.99$ to 1.15) between 1996 and 2008. Thus, the newly expanded and extended dataset produced results consistent with those reported in our previous study (Holmberg et al. 2008).

To examine the effect of length on our estimated average survival probability, we next incorporated TL as a covariate of survival in our CJS and LBJS models for 1995 to 2008. At least one estimate of total length was provided for 287 of the 386 whale sharks identified in the present study at North Ningaloo, including 121 among the returning subset. Where multiple length measurements for a given shark were available, they were averaged for modeling purposes; the resulting distribution of individual average lengths is shown in Fig. 3, which distinguishes transients from returning sharks. A small but significant disparity, independent of any modeling, between the 2 groups is evident, with transient sharks typically smaller than returning sharks by 1 to $2 \mathrm{~m}$.

This disparity between the lengths of sharks sighted in only one year and those sighted in multiple years persists at the level of discrete measurements made within the primary seasons of the $14 \mathrm{yr}$ data span, as shown in Fig. 4. For each group, median TL is dis- 
played for each year in which length measurements were available for at least 4 sharks. In every year in which a comparison is possible (10 of 14), the median TL value of the transient sharks is less than that for the returning group. Moreover, the median lengths appear to be decreasing with time, especially for the transient sharks in the later years. Although the possibility of sampling biases contributing to this temporal trend cannot be discounted (e.g. with fewer boats and spotter airplanes in the early years of NMP's ecotourism industry, smaller sharks may have been missed), such biases should apply equally to both the returning and

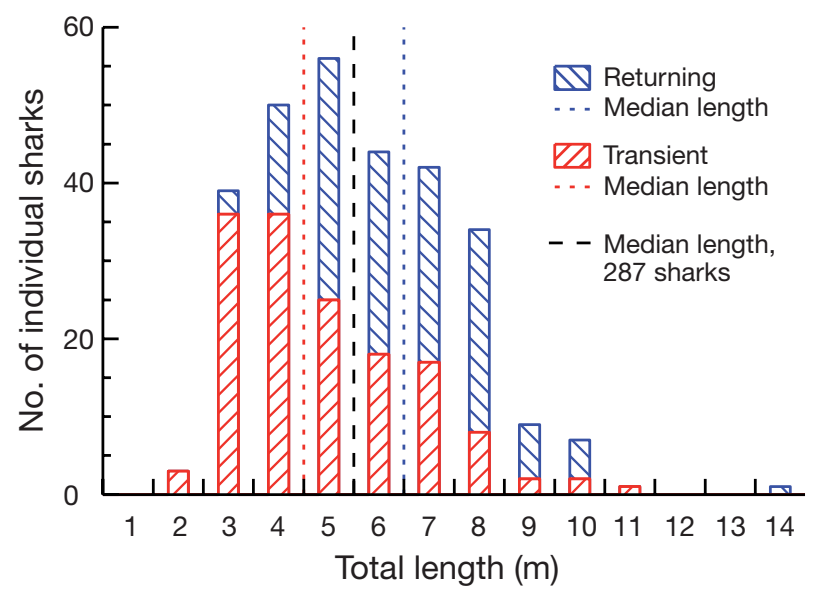

Fig. 3. Rhincodon typus. Distributions of average total length (TL) of all identified sharks, North Ningaloo 1995 to 2008. For every individual, length estimates were averaged within each season and then across all seasons where multiple reports were available. Average TL was then rounded to the nearest $\mathrm{m}$. Transient: individuals sighted in only $1 \mathrm{yr}$ in the study area; returning: individuals sighted in multiple years

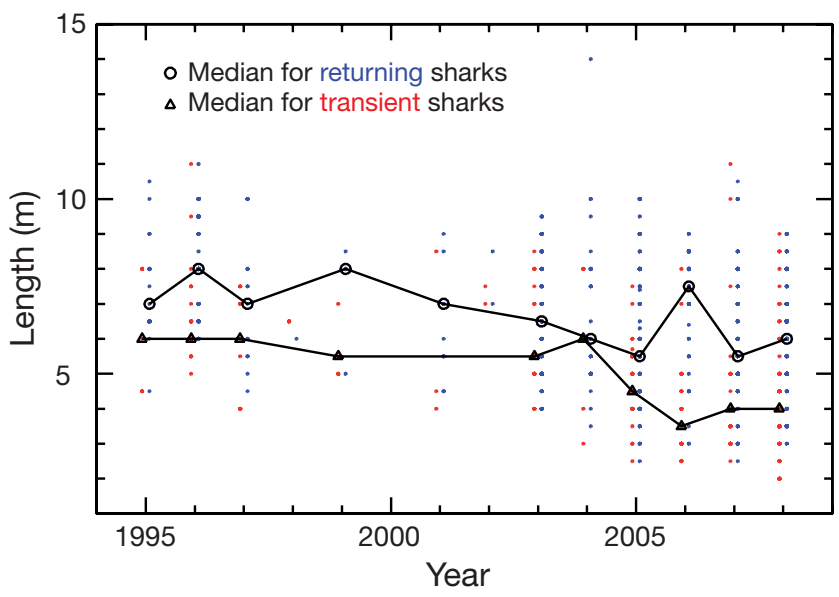

Fig. 4. Rhincodon typus. Reported lengths of individual marked whale sharks at North Ningaloo, 1995 to 2008. Small points represent measurements (single or averaged over multiple reports in each primary season); large open symbols connected by line segments show the median length for years in which 4 or more measurements were available transient populations: estimated lengths are reported at the time encounter data are submitted to the ECOCEAN Library, and the returning versus transient status of a given shark cannot readily be known to the submitter.

We subsequently ran our CJS and LBJS model structures using only those sharks with at least 1 reported length. We found a best-fit model of $\phi_{\text {new }}(\mathrm{TL}) \phi_{\text {return }}$ (TL) $p\left(t_{1}\right)$ with an $\mathrm{AIC}_{\mathrm{c}}$ weight of 0.94 compared to other model variants incorporating TL and those without it as a covariate (Table 1). Apparent survival probability as a function of TL (Fig. 5) generated an average estimate of $\phi_{\text {return }}(\mathrm{TL})$ of $0.84 \mathrm{yr}^{-1}(95 \% \mathrm{CI}=0.78$ to 0.88$)$ for a shark at our mean TL of $5.78 \mathrm{~m}$. We also found a bestfit Link-Barker Jolly-Seber model for returning sharks of $\phi_{\text {return }}(\mathrm{TL}) p_{\text {return }}\left(t_{1}\right) f_{\text {return }}(\mathrm{TL})$, as presented in Table 2 . Modeled recruitment rates as a function of TL (Fig. 5) generated an average annual recruitment rate $f_{\text {return }}(\mathrm{TL})$ of $0.23 \mathrm{yr}^{-1}$ (95\% CI $=0.17$ to 0.32$)$ for a shark at mean $\mathrm{TL}=6.5 \mathrm{~m}$, with higher recruitment rates estimated for smaller size categories. Fig. 5c also presents the average population trajectory estimated by summing the survival probability and recruitment rate for each size category under this model.

\section{ORD model selection}

Application of the ORD to our data further expanded upon our CJS-based modeling structure by integrating intraseasonal data for 287 sharks captured in eight $15 \mathrm{~d}$ sampling periods within the years 2003 to 2008. We estimated ORD parameters for a single stratum encompassing all marked individuals; ORD models require larger amounts of mark-recapture data to achieve estimates for additional intraseasonal parameters. The required volume of data was only available for 2003 to 2008, which represent years of increased data collec-

Table 1. Top 5 model rankings comparing Cormack-Jolly-Seber (CJS) model variants accounting for a survival dichotomy (including survival after the first sighted year, $\phi_{\text {new }}$ and survival between subsequent resighted years, $\phi_{\text {return }}$ ) against basic CJS models for 287 whale sharks at North Ningaloo, 1995 to 2008. Average total length (TL) is included in some models as a parameter covariate. AIC $_{\mathrm{c}}$ : corrected Akaike's Information Criterion; $t_{1}$ : annual (primary) sampling periods;

(.): constant value

\begin{tabular}{|lcc|}
\hline Model & Parameters & AIC $_{\mathrm{c}}$ weight \\
\hline$\phi_{\text {new }}(\mathrm{TL}) \phi_{\text {return }}(\mathrm{TL}) p\left(t_{1}\right)$ & 16 & 0.94 \\
$\phi_{\text {new }}(\mathrm{TL}) \phi_{\text {return }}(\mathrm{TL}) p\left(t_{1} * \mathrm{TL}\right)$ & 16 & 0.05 \\
$\phi_{\text {new }}(.) \phi_{\text {return }}() p.\left(t_{1}\right)$ & 15 & $\cong 0$ \\
$\phi\left(t_{1}, \mathrm{TL}\right) p\left(t_{1} * \mathrm{TL}\right)$ & 24 & $\cong 0$ \\
$\phi() p.\left(t_{1}\right)$ & 14 & $\cong 0$ \\
\hline
\end{tabular}




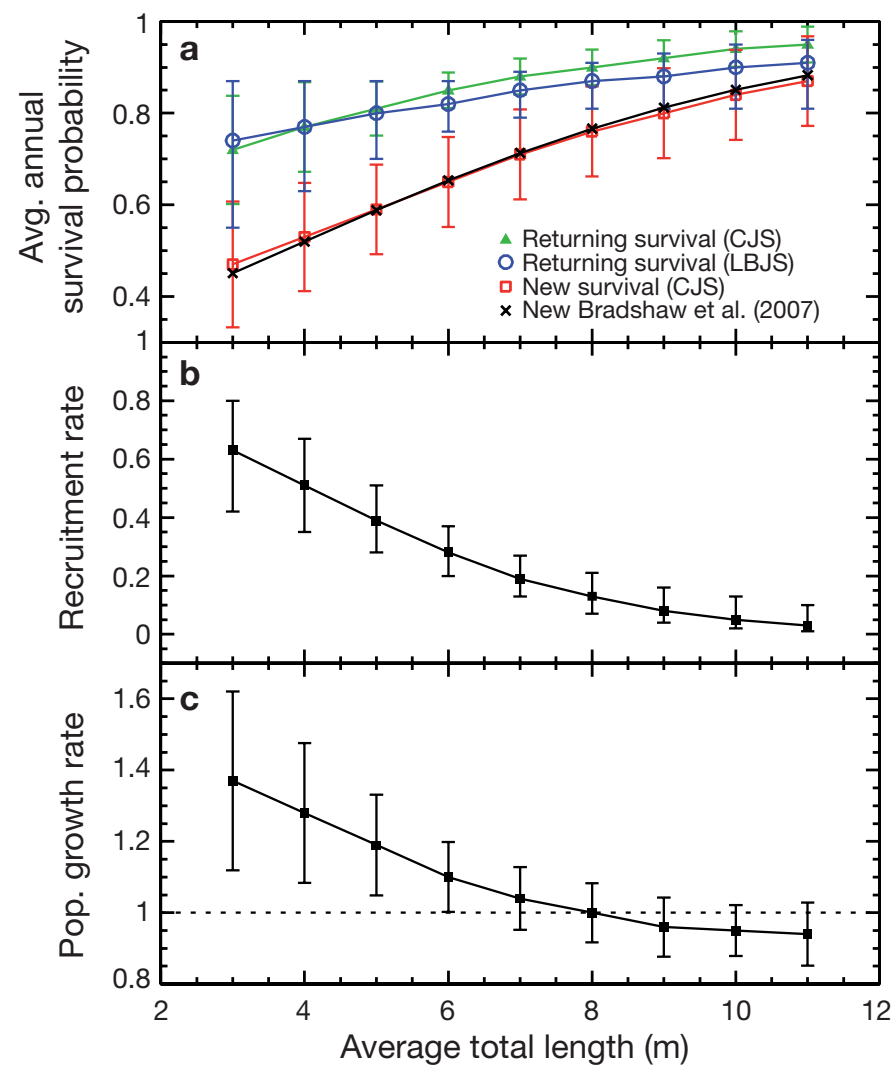

Fig. 5. Rhincodon typus. (a) Survival probability ( $\pm 95 \% \mathrm{CI})$ as a function of average total length (TL) for returning and newly marked whale sharks at North Ningaloo, Ningaloo Marine Park (NMP), 1995 to 2008. CJS: Cormack-Jolly-Seber model; LBJS: Link-Barker Jolly-Seber model. For reference, the length-survival relationship for the entire population presented by Bradshaw et al. (2007) is also included. The close match between our CJS length-survival relationship for newly marked sharks and the relationship presented in Bradshaw et al. (2007) for all NMP sharks demonstrates the confounding effect of transience: higher survival trends in the returning population can be hidden by the lower apparent survival probability of the more numerous transient individuals when the 2 groups are considered together. (b) Average annual recruitment rate $( \pm 95 \% \mathrm{CI}, \mathrm{LBJS})$ as a function of average TL for returning whale sharks at North Ningaloo, 1996 to 2008. (c) Average annual population growth rate ( $\pm 95 \% \mathrm{CI}, \mathrm{LBJS})$ as a function of average TL for returning whale sharks at North Ningaloo, 1996 to 2008

tion facilitated by more active collaboration with ecotourism activity.

Our best-fit model (Table 3) demonstrated the same survival dichotomy found in our CJS-based modeling approach: $S_{\text {new }}(.) S_{\text {return }}() p.\left(t_{2}\right)$ pent ${ }^{\mathrm{a}}\left(t_{2}\right) P h i^{\mathrm{a}}\left(t_{2}\right)$, where $\left({ }^{\mathrm{a}}\right)$ is an intraseasonal parameter constrained to a single value across all years of the model. In this structure, capture probability $(p)$ varied within annual sets of secondary sampling periods, but other intraseasonal model parameters (pent ${ }^{\mathrm{a}}$ and $P h i^{\mathrm{a}}$ ) were constrained to a single value across all years of the model instead of across all periods of a season. We note this model's predominance over models with $P \mathrm{Ph}^{\mathrm{a}}$ conditioned on TSM. This result suggests no systematic relationship between time of entry and time of exit within our dataset and lends support to our assumption of effectively instantaneous sampling. The resulting estimate for the average annual apparent survival probability for new sharks $\left(S_{\text {new }}\right.$ equivalent to the CJS $\left.\phi_{\text {new }}\right)$ was $0.48 \mathrm{yr}^{-1}(95 \% \mathrm{CI}=0.40$ to 0.56$)$, and the average annual survival probability for returning sharks $\left(S_{\text {return }}\right.$ equivalent to the CJS $\left.\phi_{\text {return }}\right)$ was $0.89 \mathrm{yr}^{-1}(95 \% \mathrm{CI}=$ 0.80 to 0.94$)$. Calculated estimates of pent ${ }^{\mathrm{a}}$ and $P h i^{\mathrm{a}}$ from the ORD describing the time-based probability of whale sharks arriving and remaining in NMP are shown in Fig. 6. Average residency time for whale sharks at NMP was estimated at 2.34 secondary periods (95\% CI $=2.08$ to 2.61 ) or $35 \mathrm{~d} \mathrm{yr}^{-1}$. Resulting estimates of annual abundance from the best-fit ORD model are listed in Table 4.

We also examined average TL as a covariate to $S$, Phi, and pent for 224 whale sharks for which at least 1 TL was reported from 2003 to 2008 . We allowed the relationship between TL and each parameter to vary with time and explored a constant relationship alternative. Our top-ranked model, $S_{\text {new }}(\mathrm{TL}) S_{\text {return }}(\mathrm{TL}) p\left(t_{2}\right)$ pent $^{\mathrm{a}}\left(t_{2}\right) P h \mathrm{i}^{\mathrm{a}}\left(t_{2}\right)$, is presented in Table 5. Estimates of abundance under this model (Table 4) were somewhat smaller than those suggested by the top-ranked ORD model without TL as a covariate. Average residency time was estimated at 2.47 secondary periods (95\% CI $=1.91$ to 3.02 ) or $37 \mathrm{~d}$.

\section{DISCUSSION}

Our previous study (Holmberg et al. 2008) presented a CMR approach to modeling the population at NMP; we have built upon that approach here. The use of time-series data under CJS and LBJS models can generate estimates of apparent survival probability and recruitment rates without a reliance on poorly understood life history parameters. Additionally, this approach has the advantage of accounting for the effect of transience on apparent survival probability. Integration of individual covariates into these models, such as TL, allows for the further exploration of averaged estimates and exposes underlying trends, such as the size categories contributing to recruitment.

In the present study, we found no evidence of a decline in whale shark abundance at North Ningaloo in apparent contrast to previous reports (Bradshaw et al. 2007, 2008). Differences in model estimates and timeframes, however, leave some room for reconciliation. Bradshaw et al. (2007) suggest a declining annual 
Table 2. Top 5 model rankings comparing Link-Barker Jolly-Seber model variants for 121 returning whale sharks at North Ningaloo, 1996 to 2008. Average total length (TL) is included in some models as a parameter covariate of survival $(\phi)$, capture probability $(p)$, and recruitment $(f)$. AIC $\mathrm{A}_{\mathrm{c}}$ : corrected Akaike's Information Criterion; $t_{1}$ : annual (primary) sampling periods

\begin{tabular}{|c|c|c|c|}
\hline Model & Parameters & $\mathrm{AIC}_{\mathrm{c}}$ weight & $\begin{array}{c}f(95 \% \mathrm{CI}) \\
\text { at average } \\
6.5 \mathrm{~m} \mathrm{TL}\end{array}$ \\
\hline$\phi_{\text {return }}(\mathrm{TL}) p_{\text {return }}\left(t_{1}\right) f_{\text {return }}(\mathrm{TL})^{\mathrm{a}}$ & 17 & 0.34 & $\begin{array}{c}0.23 \\
(0.17-0.32)\end{array}$ \\
\hline$\phi_{\text {return }}(.) p_{\text {return }}\left(t_{1}\right) f_{\text {return }}(\mathrm{TL})^{\mathrm{a}}$ & 16 & 0.33 & $\begin{array}{c}0.23 \\
(0.16-0.31)\end{array}$ \\
\hline$\phi_{\text {return }}(\mathrm{TL}) p_{\text {return }}\left(t_{1} * \mathrm{TL}\right) f_{\text {return }}(\mathrm{TL})$ & 16 & 0.20 & $\begin{array}{c}0.24 \\
(0.17-0.33)\end{array}$ \\
\hline$\phi_{\text {return }}(.) p_{\text {return }}\left(t_{1} * \mathrm{TL}\right) f_{\text {return }}(\mathrm{TL})$ & 16 & 0.13 & $\begin{array}{c}0.23 \\
(0.17-0.32)\end{array}$ \\
\hline$\phi_{\text {return }}(.) p_{\text {return }}\left(t_{1}\right) f_{\text {return }}()$. & 15 & $\cong 0$ & $\begin{array}{c}0.24 \\
(0.17-0.31)\end{array}$ \\
\hline
\end{tabular}

Table 3. Top 5 model rankings in MARK comparing Open Robust Design (ORD) variants for 287 whale sharks at North Ningaloo, 2003 to 2008. For Phi under the ORD, where $t_{2}$ represents $2 \mathrm{wk}$ intraseasonal (secondary) sampling periods, we examined scenarios of time dependence, $P h i\left(t_{2}\right)$; time dependence for each secondary period averaged across years, $P h i^{\mathrm{a}}\left(t_{2}\right)$; time invariance within secondary periods, Phi(.); and time since marking, Phi(TSM). With a TSM analysis, estimates of Phi are conditioned on when an individual was first marked, probing whether the time of departure for a whale shark at NMP is linked to its arrival time on the reef. Only models for which all parameters were estimable were considered. $\mathrm{AIC}_{\mathrm{c}}$ : corrected Akaike's Information Criterion; $S$ : average annual apparent survival probability for new sharks, $S_{\text {new }}$ and returning sharks, $S_{\text {returni }}$ pent: probability of entry into the study area. ${ }^{a}$ : intraseasonal parameter constrained to a single value across all years of the model

\begin{tabular}{|c|c|c|}
\hline Model & Parameters & $\mathrm{AIC}_{\mathrm{c}}$ weight \\
\hline$S_{\text {new }}(.) S_{\text {return }}() p.\left(t_{2}\right)$ pent $^{\mathrm{a}}\left(t_{2}\right) P h i^{\mathrm{a}}\left(t_{2}\right)$ & 60 & 0.82 \\
\hline$S_{\text {new }}(.) S_{\text {return }}(\mathrm{TSM}) p\left(t_{2}\right)$ pent $^{\mathrm{a}}\left(t_{2}\right) P h i^{\mathrm{a}}\left(t_{2}\right)$ & 61 & 0.14 \\
\hline$S_{\text {new }}(.) S_{\text {return }}(\mathrm{TSM}) \varnothing\left(t_{2}\right)$ pent $^{\mathrm{a}}\left(t_{2}\right) P h i^{\mathrm{a}}\left(\mathrm{TSM} * t_{2}\right)$ & 61 & 0.02 \\
\hline$S_{\text {new }}(.) S_{\text {return }}() p.\left(t_{2}\right)$ pent $^{\mathrm{a}}\left(t_{2}\right) P h i^{\mathrm{a}}\left(\mathrm{TSM} * t_{2}\right)$ & 62 & 0.02 \\
\hline$S() p.\left(t_{2}\right)$ pent $^{\mathrm{a}}\left(t_{2}\right)$ Phi $^{\mathrm{a}}\left(t_{2}\right)$ & 59 & $\cong 0$ \\
\hline
\end{tabular}

in the context of a larger decline. Such reconciliation, if it assumes all reports are accurate, would require the preceding overall decline to occur within the transient subset of sharks sighted in only one season. Further seasons of modeling data using the ORD can test such a reconciliation of estimates.

For reasons elaborated below, we believe that previous reports of a decline should be treated with caution. Of critical importance to the agebased Leslie Matrix model approach used by Bradshaw et al. (2007) is knowledge of some poorly understood life history parameters, including litter size of precocial pups, female reproduction frequency, age-specific survival probability, age in years, age at first reproduction, and maximum age in years. For litter size, only one data point exists in the published literature: 300 for an $11 \mathrm{~m}$ female (Joung et al. 1996). No understanding is currently available for how this number may vary with size. Given a projected maximum size for whale sharks of approximately $14 \mathrm{~m}$ (Compagno 2001) and the likelihood that increases in length yield increased fecundity, a survival strategy demonstrated in shark species producing large litters (Cortés 2000, E. Cortés pers. comm.), the value of Joung et al. (1996) may not approximate an average for whale sharks.

Estimation of age for whale sharks, such as age at primiparity, current age, or maximum age, is a challenge and is heavily dependent upon uncertain rates of growth, since only TL is available as a measurement in the

abundance of all NMP whale sharks during the period 1992 to 2004. Our LBJS approach compensates for the transience that we have uncovered by estimating only the fractional annual change in abundance of a returning subset of sharks that can be captured in more than one season, reporting marginal growth in the population size of this subset from 1996 to 2008. In contrast, our ORD abundance estimates for 2004 to 2007 apply to the full set of transient and returning sharks, providing some limited, recent evidence for overall population growth. These ORD results lie outside of the time frame of Bradshaw et al. (2007) and may indicate a later population recovery after a decline in total (but not returning) abundance or just a short-term increase wild and from published literature (Colman 1997, Meekan et al. 2006, Norman \& Stevens 2007). Agespecific survival probabilities are also unknown for whale sharks. Breeding habits for whale sharks have not been documented, and small whale sharks $(<3 \mathrm{~m})$ are infrequently sighted (Rowat et al. 2008). In the absence of empirical evidence, Bradshaw et al. (2007) cross-applied a first-year survival probability for juvenile whale sharks of $0.5 \mathrm{yr}^{-1}$ from estimates of juvenile lemon sharks Negaprion brevirostris and black-tip sharks Carcharhinus limbatus. We raise 2 challenges to this assumption.

First, lemon sharks and black-tip sharks give birth to far fewer young than the whale shark, with numbers of 

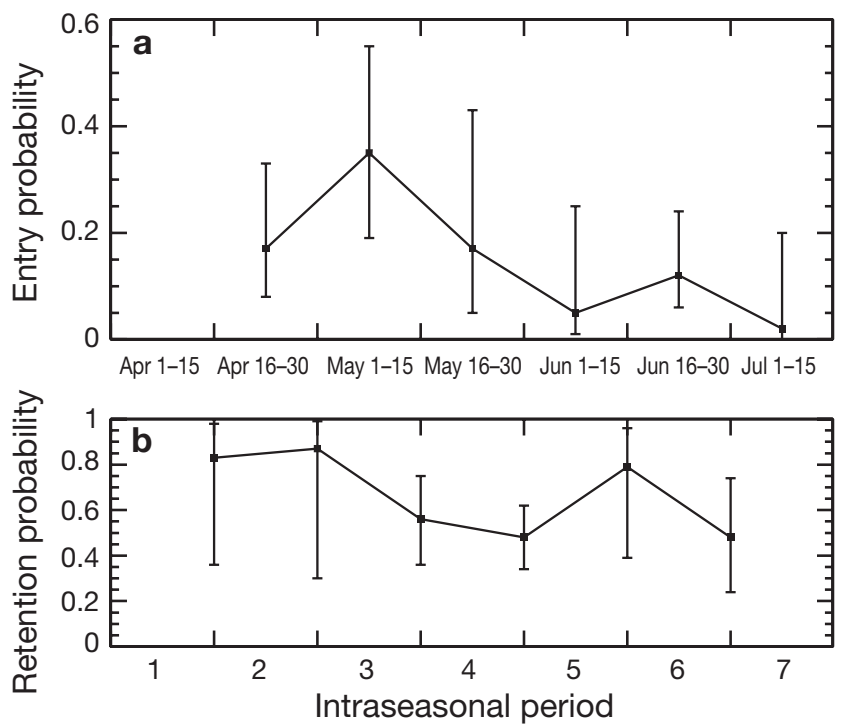

Fig. 6. Rhincodon typus. (a) Average biweekly entry profiles (pent) for whale sharks at North Ningaloo, 2003 to 2008, showing the probability that a whale shark arrives in the study area during the specified time period. The probability for the first secondary period cannot be estimated under this model. pent values estimated here are averages across all years of the study for each secondary period. (b) Average biweekly retention profiles $\left(P h i_{i} \pm 95 \% \mathrm{CT}\right)$ for whale sharks at North Ningaloo, 2003 to 2008. Each value represents the probability that a whale shark remains in the North Ningaloo study area between the specified secondary sampling periods. We note that the 7 th value is confounded under this model structure. Phi values estimated here are averaged across all years of the study. Error bars are $95 \%$ CI

Table 4. Annual abundance of whale sharks visiting the North Ningaloo study area each year, as estimated in the best-fit Open Robust Design (ORD) model variants, $S_{\text {new }}(.) S_{\text {return }}()$. $\left(t_{2}\right)$ pent ${ }^{\mathrm{a}}\left(t_{2}\right) P h i^{\mathrm{a}}\left(t_{2}\right)$ and $S_{\text {new }}(\mathrm{TL}) S_{\text {return }}(\mathrm{TL}) p\left(t_{2}\right)$ pent $^{\mathrm{a}}\left(t_{2}\right) P h i^{\mathrm{a}}$ $\left(t_{2}\right)$ (see Table 5), for 2003 to 2008. 95\% CI are provided in parentheses. Estimates of total annual abundance generated via the ORD using the Jolly-Seber modeling approach are often negatively biased due to heterogeneity in capture (Pollock et al. 1990). Based on Test 2 results, we expect the bias to be slight and well within the range of the listed confidence intervals. Abundance values for the first and last years are confounded under this model (Schwarz \& Stobo 1997). N/A: not available

\begin{tabular}{|ccc|}
\hline Year & $\begin{array}{c}\text { Abundance (N) } \\
\text { without length as } \\
\text { a covariate }\end{array}$ & $\begin{array}{c}\text { Abundance (N) } \\
\text { with length as } \\
\text { a covariate }\end{array}$ \\
\hline 2003 & N/A & N/A \\
2004 & $107(90-124)$ & $86(72-100)$ \\
2005 & $119(103-133)$ & $96(82-111)$ \\
2006 & $153(120-186)$ & $128(100-156)$ \\
2007 & $177(127-190)$ & $143(112-173)$ \\
2008 & N/A & N/A \\
\hline
\end{tabular}

Table 5. Top 5 model rankings comparing Open Robust Design variants for 224 whale sharks at North Ningaloo, 2003 to 2008. In these models, average total length (TL) was examined as a covariate of $P h i$ (probability of remaining in the study area), pent (average probability of entry within a secondary period), and $S$ (average annual apparent survival probability). Only models for which all parameters were estimable were considered. $\mathrm{AIC}_{\mathrm{c}}$ : corrected Akaike's Information Criterion; $t_{2}: 2$ wk intraseasonal (secondary) sampling periods; ${ }^{\text {a }}$ : intraseasonal parameter constrained to a single value across all years of the model ${ }_{\mathrm{v}}$ : the relationship between TL and the model parameter was allowed to vary with time; TSM: time since marking

\begin{tabular}{|lcc|}
\hline Model & $\begin{array}{c}\text { Para- } \\
\text { meters }\end{array}$ & $\begin{array}{c}\text { AIC } \\
\text { weight }\end{array}$ \\
\hline$S_{\text {new }}(\mathrm{TL}) S_{\text {return }}(\mathrm{TL}) p\left(t_{2}\right) p e n t^{\mathrm{a}}\left(t_{2}\right) P h i^{\mathrm{a}}\left(t_{2}\right)$ & 63 & 0.78 \\
$S_{\text {new }}(.) S_{\text {return }}() p.\left(t_{2}\right) p e n t^{\mathrm{a}}\left(t_{2}\right) P h i^{\mathrm{a}}\left(t_{2}\right)$ & 60 & 0.12 \\
$S_{\text {new }}(.) S_{\text {return }}() p.\left(t_{2}\right) p e n t^{\mathrm{a}}\left(\mathrm{TL}_{\mathrm{v}} * \mathrm{t}_{2}\right) P h i^{\mathrm{a}}\left(\mathrm{TL}_{\mathrm{v}} * t_{2}\right)$ & 72 & 0.09 \\
$S_{\text {new }}(.) S_{\text {return }}() p.\left(t_{2}\right) p e n t^{\mathrm{a}}\left(\mathrm{TL}_{\mathrm{v}} * \mathrm{t}_{2}\right) P h i^{\mathrm{a}}\left(t_{2}\right)$ & 65 & 0.01 \\
$S_{\text {new }}(.) S_{\text {return }}() p.\left(t_{2}\right)$ pent $^{\mathrm{a}}\left(t_{2}\right) P h i^{\mathrm{a}}(\mathrm{TSM})$ & 60 & $\cong 0$ \\
\hline
\end{tabular}

pups generally $<20$ (Feldheim et al. 2002, Keeney et al. 2003). If producing large numbers of pups is a survival strategy of whale sharks to compensate for low pup survival rates as demonstrated in other shark species with large litter sizes (Cortés 2000), such as the pelagic blue shark Prionace glauca, then a first-year survival probability cross-applied from pups of much smaller shark species with different life histories and significantly lower fecundity is questionable.

Second, Bradshaw et al. (2007) assumed that annual survival probabilities modestly increase from $0.5 \mathrm{yr}^{-1}$ for a whale shark pup in the first year $(\cong 1.4 \mathrm{~m})$ to $0.59 \mathrm{yr}^{-1}$ at $5 \mathrm{~m}$ and then jump to $0.81 \mathrm{yr}^{-1}$ at $9 \mathrm{~m}$. However, they also presented an equation relating total length to apparent survival (depicted here in Fig. 5) that suggests different, lower values for first-year survival when extrapolated to neonatal length. Using the provided estimates of $0.8 \mathrm{~m}$ first-year growth in TL and a fetal length of 42 to $63 \mathrm{~cm}$ (Joung et al. 1996, Chang et al. 1997), we obtain a projected first-year survival probability between 0.296 (63 $\mathrm{cm}_{\text {; }}$ pup) and 0.344 ( $1.4 \mathrm{~m}$; 1 yr old juvenile) using their equation. As Bradshaw et al. (2007) noted, this equation was not generated from data specific to neonatal whale sharks; we contend, based on the trends evident in Fig. 5, that the decrease in survival probability with decreasing TL may be even more precipitous, given the previously discussed life history traits of the species. We also note the remarkably close correspondence between the TL-survival relationship presented by Bradshaw et al. (2007) and our TL-survival relationship for newly marked individuals (Fig. 5a), which accounts for both transience and apparent first-year survival. Noting the large number of sharks sighted in only one season (an 
approximately $2: 1$ ratio of transient to returning sharks, as reported in Holmberg et al. 2008), this comparison demonstrates the confounding effect of transience (a negative bias) on the survival probabilities estimated in previous reports of declines. Further exploration of both of these factors is needed.

We present here a first integration of intraseasonal data for whale sharks into population modeling via the ORD. This approach accounts for previously detected transience (Holmberg et al. 2008) and allows for the examination of behavioral dynamics (Schwarz \& Stobo 1997), such as average residency time and probabilities of entry and exit. Its ability to estimate total annual abundance can also be used in the future to reconcile trends in abundance within the returning subset of sharks with overall population projections. We therefore believe this approach to hold great promise, and future studies should attempt to incorporate other potentially relevant environmental covariates, such as water temperature or coral spawning dates, to better understand their effects on modeled parameters. However, we note that even with close collaboration with ecotourism, we could not estimate time variance of some basic model parameters. Usage of the ORD model structure for whale sharks requires relatively large amounts of centralized and standardized markrecapture data to estimate key parameters, and subsequent studies should work to maintain or increase current levels of data collection at NMP. This is a significant challenge for a rare species with a small local aggregation size. Research at other similarly large whale shark aggregation points, such as Mexico, the Philippines, and Mozambique, may also benefit from the ORD as presented here. Locations with apparently smaller aggregations, such as Belize, Honduras, the Maldives, Thailand, and the Galapagos Islands, may need to reduce sampling occasions to achieve a good balance between available data and the number of estimated parameters.

Our estimates of total annual abundance (N) approach the estimate of 200 ind. reported by Taylor (1994). We note, however, that the present study was strictly limited to whale sharks captured at North Ningaloo, while the geographical boundaries within NMP of earlier studies (Taylor 1994, Meekan et al. 2006) are not well specified and may not represent the same sampling area. The number of estimable years of abundance in the present study is limited by confounding of initial and final estimates under the ORD and by the larger amounts of data required for the model structure. The increasing trend in abundance under the ORD in the present study modestly reinforces the $13 \mathrm{yr}$ estimated trend of minimally increasing population size for North Ningaloo's returning sharks calculated under the LBJS model. However, because esti- mated abundance under the ORD covers all marked individuals, our results also suggest a modestly increasing total annual population size in the later years of the present study. This short-term trend may also represent a temporary increase within a long-term decline if it can be reconciled with the declines in overall total abundance reported by Bradshaw et al. (2007, 2008).

The ORD has significant potential to support multisite CMR (Nichols \& Kendall 1995, Kendall \& Bjorkland 2001) for whale sharks when sufficient movement data is available in the future. For example, multiple strata in the ORD permit the integration of CMR data from distant sites outside of NMP, allowing strata transitions to represent the probabilities of migration to one of many potential aggregation points. Such usage of the ORD, similar to the multi-state analysis presented by Brownie et al. (1993) for Canada geese Branta canadensis, would permit integrated modeling of local apparent survival rates, annual regional abundance, and migration probabilities between sites. Thus, use of the ORD model here and in future NMP whale shark studies provides a path to regional analyses if and when multi-site data become available.

The median reported length for whale sharks at North Ningaloo declined slowly over the course of the present study. The trend is weak, but these results appear to corroborate the decline in TL reported by Bradshaw et al. (2008). However, our confirmation is made using an independent dataset which suggests a substantially different explanation from that previously provided for this decline (i.e. 'reductions in the number of large individuals in the population') by Bradshaw et al. (2008). Given the small apparent increases in returning shark abundance (1996-2008) and total abundance (2004-2007), we present an alternative hypothesis: a decline in average TL for new and returning sharks, coupled with an increase in the number of sharks returning to North Ningaloo, may indicate increased recruitment of smaller individuals, as already indicated by our LBJS model's length-based recruitment estimates (Fig. 5).

Increased recruitment of smaller individuals into North Ningaloo could result from a population recovery after exploitation elsewhere on a migratory route, a natural population fluctuation, changes in movement patterns of younger individuals, or other environmental factors increasing pup survival. For example, declines in populations of predators of whale shark pups, such as the blue shark Prionace glauca or the blue marlin Makaira nigricans (Colman 1997), may facilitate increased pup survival probabilities and therefore increased recruitment of smaller individuals at NMP. Globally reported declines in the populations of other shark species (Baum et al. 2003, Myers \& 
Worm 2003, Myers et al. 2007) that may be predators on small whale shark pups may facilitate such a mechanism. However, independent verification of factors affecting pup survival is extremely difficult. Whale shark mating and birthing have yet to be documented or even verifiably observed. Similarly, early whale shark behavior remains a mystery, with few reports of sightings of whale sharks $<3$ m (Rowat et al. 2008, ECOCEAN Library at www.whaleshark.org). An attractive feature of the hypothesis that smaller, younger sharks are being recruited into the returning NMP population is that it is testable under our model structure: continued monitoring over years and decades should demonstrate recapture of the recruited sharks and, with sufficiently accurate length measurements, reveal their growth rate as their lengths approach those of the older, established NMP population.

We note that there is currently no broad perception of a decline in whale shark abundance among ecotourism operators and marine park managers in North Ningaloo (R. Mau pers. comm.), though these are not scientifically rigorous assessments. Rather, it is worth reiterating that whale sharks are large animals that are easily observed during the annual season. Barring unknown systematic effects, declines in abundance (translated as increased effort to find sharks) should be apparent to the ecotourism community. While Bradshaw et al. (2008) found such an increase in required effort, by modeling operator logs independently collected by the local Department of Environmental Conservation (DEC), the corresponding ecotourism industry does not echo these concerns. $\underline{1}$

Our ongoing mark-recapture study demonstrates a comprehensive data collection, analysis, and modeling approach for whale shark mark-recapture research that can be replicated and tested at other aggregation points. This approach can also be built upon and continuously tested in future seasons at NMP without continuing reliance on poorly understood life history parameters. Further management of research efforts at North Ningaloo should ensure the continuation of high levels of data collection to support more complex models, such as the ORD, and establish the importance of related environmental covariates. Additionally, new avenues to reliably, inexpensively, and comprehensively measure annual lengths for large numbers of marked individuals are needed to accurately explore length as a covariate in CMR models. The highly uncertain TL estimates of untrained observers can be meaningful en masse, but they

\footnotetext{
${ }^{1}$ The DEC does not recommend the usage of these operator log data for effort analysis (Mau \& Wilson 2005, R. Mau pers. comm.), and they note the shifting of whale shark peak occurrence times outside of the April-May analysis period of Bradshaw et al. (2008).
}

are unreliable for more sophisticated modeling approaches requiring accurate, continuous estimates for each individual (Bonner \& Schwarz 2006).

Given the highly migratory nature of whale sharks, further work at NMP must also begin to more effectively explore whale shark ecology beyond its boundaries. While the local population trajectory may be flat or modestly increasing, the explanation of the dynamic is uncertain, and therefore further management steps - beyond continued regulation of ecotourism - are opaque. Regional coordination of research is imperative to understand larger pressures on this and other highly migratory species. However, until mark-recapture study sites can be linked, multi-site analyses, such as those potentially available under the ORD, are unavailable. Localized studies, such as this one, must continue to inform management decisions at NMP and elsewhere. When sufficient data are available for broader analyses, collaborative efforts, such as the ECOCEAN Whale Shark Photo-identification Library, and multi-state models are well suited for integrating local population trajectories into regional and global analyses.

Acknowledgements. We thank S. Bonner and C. Schwarz for their advisory roles and for patient reviews of our manuscript and models. We also thank 4 anonymous peer reviewers for suggestions, from which we greatly benefited. Project research assistants gave invaluable support, including G. Shedrawi and H. Shortland-Jones. Significant data were donated by L. Alsop, S. Quasnichka, A. Richards, P. and K. Waghorn, K. Anderson, L. Holtzman, R. Todd, and the 2006, 2007, and 2008 volunteers of the Earthwatch Institute. The following organizations also provided support: the Rolex Awards for Enterprise, the British Ecological Society, and the Earthwatch Institute. Data collection for the present study was performed in accordance with the Murdoch University Code of Animal Ethics (www.research.murdoch.edu.au/ ethics/arec/animalethics.html) and the Australian Code of Practice for the Care and Use of Animals for Scientific Purposes, 7th edn 2004 (www.nhmrc.gov.au/publications/synopses/ea16syn.htm).

\section{LITERATURE CITED}

Akaike H (1973) Information theory and an extension of the maximum likelihood principle. In: Petrov BN, Csaki F (eds) Second Int Symp Information Theory. Akademiai Kiado, Budapest, p 267-281

Arzoumanian Z, Holmberg J, Norman B (2005) An astronomical pattern-matching algorithm for computer-aided identification of whale sharks Rhincodon typus. J Appl Ecol 42:999-1011

Baum JK, Myers RA, Kehler DG, Worm B, Harley SJ, Doherty PA (2003) Collapse and conservation of shark populations in the Northwest Atlantic. Science 299:389-392

Bonner SJ, Schwarz CJ (2006) An extension of the CormackJolly-Seber model for continuous covariates with application to Microtus pennsylvanicus. Biometrics 62:142-149

Bradshaw CJA, Mollet HF, Meekan MG (2007) Inferring population trends for the world's largest fish from markrecapture estimates of survival. J Anim Ecol 76:480-489 
Bradshaw CJA, Fitzpatrick BM, Steinberg CC, Brook BW, Meekan MG (2008) Decline in whale shark size and abundance at Ningaloo Reef over the past decade: the world's largest fish is getting smaller. Biol Conserv 141:1894-1905

Brownie C, Hines JE, Nichols JD, Pollock KH, Hestbeck JB (1993) Capture-recapture studies for multiple strata including non-Markovian transitions. Biometrics 49: 1173-1187

Burnham KP, Anderson DR, White GC, Brownie C, Pollock KH (1987) Design and analysis methods for fish survival experiments based on release-recapture. Am Fish Soc Monogr No. 5, Am Fish Soc, Bethesda, MD

Burnham KP, Anderson DR (1992) Data-based selection of an appropriate biological model: the key to modern data analysis. In: McCullough DR, Barrett RH (eds) Wildlife 2001: populations. Elsevier Applied Science, New York, p 16-30

Burnham KP, Anderson DR (1998) Model selection and inference: a practical information-theoretic approach. Springer-Verlag, New York

Cailliet GM, Smith WD, Mollet HF, Goldman KJ (2006) Age and growth studies of chondrichthyan fishes: the need for consistency in terminology, verification, validation, and growth function fitting. Environ Biol Fishes 77:211-228

- Castro ALF, Stewart BS, Wilson SG, Hueter RE and others (2007) Population genetic structure of Earth's largest fish, the whale shark (Rhincodon typus). Mol Ecol 16: 5183-5192

Chang WB, Leu MY, Fang LS (1997) Embryos of the whale shark, Rhincodon typus: early growth and size distribution. Copeia 2:444-446

CITES (2002) Inclusion of the whale shark (Rhincodon typus) in Appendix II of CITES. Proponents: India and the Philippines. Prop 12.35, available at www.cites.org/eng/cop/ 12/prop/E12-P35.pdf

Colman JG (1997) A review of the biology and ecology of the whale shark. J Fish Biol 51:1219-1234

Compagno LJV (2001) Sharks of the world. An annotated and illustrated catalogue of shark species known to date. Vol 2. Bullhead, mackerel and carpet sharks (Heterodontiformes, Lamniformes and Orectolobiformes). FAO Species Catalogue for Fishery Purposes No. 1, Vol 2. FAO, Rome

Cortés E (2000) Life-history patterns and correlations in sharks. Rev Fish Sci 8:299-344

Crosbie SF, Manly BF (1985) Parsimonious modeling of capture-mark-recapture studies. Biometrics 41:385-398

Feldheim KA, Gruber SH, Ashley MV (2002) The breeding biology of lemon sharks at a tropical nursery lagoon. Proc R Soc Lond B Biol Sci 269:1655-1661

Graham R, Roberts C (2007) Assessing the size, growth rate and structure of a seasonal population of whale sharks (Rhincodon typus Smith 1828) using conventional tagging and photo identification. Fish Res 84:71-80

Holmberg J, Norman B, Arzoumanian Z (2008) Robust, comparable population metrics through collaborative photomonitoring of whale sharks Rhincodon typus. Ecol Appl $18: 222-233$

IUCN International Union for Conservation of Nature (2008) Red List of Threatened Species. www.iucnredlist.org/ (accessed 20 August 2008)

Jolly GM (1965) Explicit estimates from capture-recapture data with both death and immigration: stochastic model. Biometrika 52:225-247

Joung SJ, Chen CT, Clark E, Uchida S, Huang WYP (1996) The whale shark, Rhincodon typus, is a livebearer: 300 embryos found in one 'megamamma' supreme. Environ Biol Fishes 46:219-223

Kendall WL, Bjorkland R (2001) Using open robust design models to estimate temporary emigration from capturerecapture data. Biometrics 57:1113-1122
Keeney DB, Heupel DR, Hueter RE, Heist EJ (2003) Genetic heterogeneity among blacktip shark, Carcharhinus limbatus, continental nurseries along the U.S. Atlantic and Gulf of Mexico. Mar Biol 143:1039-1046

Lebreton JD, Burnham KP, Clobert J, Anderson DR (1992) Modeling survival and testing biological hypotheses using marked animals: case studies and recent advances. Ecol Monogr 62:67-118

Link WA, Barker RJ (2005) Modeling association among demographic parameters in analysis of open population capture-recapture data. Biometrics 61:46-54

Mau R, Wilson E (2005) Industry trends and whale shark ecology based on tourism operator logbooks at Ningaloo Marine Park. In: Irvine TR, Keesing JK (eds) Proc First Int Whale Shark Conf, Perth, Western Australia, 9-12 May 2005. CSIRO Marine and Atmospheric Research, Wembley, p 45-52

- Meekan MG, Bradshaw CJA, Press M, McLean C, Richards A, Quasnichka S, Taylor JG (2006) Population size and structure of whale sharks Rhincodon typus at Ningaloo Reef, Western Australia. Mar Ecol Prog Ser 319:275-285

- Myers RA, Worm B (2003) Rapid worldwide depletion of predatory fish communities. Nature 423:280-283

> Myers RA, Baum JK, Shepherd TD, Powers SP, Peterson CH (2007) Cascading effects of the loss of apex predatory sharks from a coastal ocean. Science 315:1846-1850

Nichols JD, Kendall WL (1995) The use of multi-state capturerecapture models to address questions in evolutionary ecology. J Appl Stat 22:835-846

Norman BM (1999) Aspects of the biology and ecotourism industry of the whale shark Rhincodon typus in northwestern Australia. MPhil thesis, Murdoch University

> Norman BM, Stevens JD (2007) Size and maturity status of the whale shark (Rhincodon typus) at Ningaloo Reef in Western Australia. Fish Res 84:81-86

Otis DL, Burnham KP, White GC, Anderson DR (1978) Statistical inference for capture data on closed animal populations. Wildl Monogr 62

Pollock KH, Nichols JD, Brownie C, Hines JE (1990) Statistical inference for capture-recapture experiments. Wildl Monogr 107

> Pradel R, Hines JE, Lebreton JD, Nichols JD (1997) Capturerecapture survival models taking account of transients. Biometrics 53:60-72

Rowat D, Gore MA, Baloch BB, Islam Z and others (2008) New records of neonatal and juvenile whale sharks (Rhincodon typus) from the Indian Ocean. Environ Biol Fishes 82: $215-218$

> Schwarz CJ, Stobo WT (1997) Estimating temporary migration using the robust design. Biometrics 53:178-194

> Seber GAF (1965) A note on the multiple recapture census. Biometrika 52:249-259

Smith DR, Anderson DR (1987) Effects of lengthy ringing periods on estimators of annual survival. Acta Ornithol 23: 69-76

- Stanley TR, Burnham KP (1999) A closure test for time-specific capture-recapture data. Environ Ecol Stat 6:197-209

Taylor JG (1994) Whale sharks. Angus \& Robertson Publishers, Sydney

Taylor JG (1996) Seasonal occurrence, distribution and movements of the whale shark, Rhincodon typus, at Ningaloo Reef, Western Australia. Mar Freshw Res 47:637-642

Theberge MM, Dearden P (2006) Detecting a decline in whale shark Rhincodon typus sightings in the Andaman Sea, Thailand, using ecotourist operator-collected data. Oryx 40:337-342

Uchida S, Toda M, Kamei Y, Teruya H (2000) The husbandry of 16 whale sharks Rhincodon typus from 1980 to 1998 at the Okinawa Expo Aquarium. Abstracts. Am Elasmo- 
branch Soc Whale Shark Symp, La Paz, Mexico, 14-18 June 2000

- Van Tienhoven AM, Den Hartog JE, Reijns RA, Peddemors VM (2007) A computer-aided program for pattern-matching natural marks on the spotted raggedtooth shark Carcharias taurus (Rafinesque, 1810). J Appl Ecol 44:273-280

Editorial responsibility: Brendan Godley, University of Exeter, Cornwall Campus, UK
White GC, Burnham KP (1999) Program MARK: Survival estimation from populations of marked animals. Bird Study 46:120-138

Williams BK, Nichols JD, Conroy MJ (2002) Analysis and management of animal populations. Academic Press, San Diego, CA

Submitted: July 29, 2008; Accepted: January 28, 2009 Proofs received from author(s): March 23, 2009 